\title{
Intervening to Prevent Nighttime Injuries in Cognitively- Impaired Persons Living at Home: A Case Report
}

\section{Rowe}

\section{Citation}

M Rowe. Intervening to Prevent Nighttime Injuries in Cognitively-Impaired Persons Living at Home: A Case Report. The Internet Journal of Advanced Nursing Practice. 1998 Volume 3 Number 2.

\begin{abstract}
The purpose of this case report is to illustrate the use of a novel interventio $\mathrm{n}$ used to prevent injuries in cognitively-impaired $(\mathrm{Cl})$ individuals living in $\mathrm{t}$ he home who arise during the night. A home monitoring system was developed to e nsure that the caregiver would be notified if the $\mathrm{Cl}$ individual attempted to le ave the home at night. This case illustrates the effectiveness of the device in a situation in which the $\mathrm{Cl}$ individual frequently attempted to leave the home during the night hours.
\end{abstract}

Correspond and request reprints to:

Meredeth A. Rowe, RN, PhD

Decker School of Nursing

Binghamton University

Binghamton, NY 13902-1600

Grant support received from:Zeta Iota Chapter of Sigma

Theta Tau; Decker Foundation; Faculty Development and Enhancement Grant, Binghamton University

\section{CLINICAL SIGNIFICANCE}

As the general population ages, the number of cognitivelyimpaired (CI) individuals will rise exponentially over the next 30 years placing a significant toll on caregivers and long term care institutions. Currently approximately 4 million individuals with Alzheimer's disease and other cognitive impairments live in the United States with this number increasing by several hundred thousand in the next 5 years, and by more than a million in the next 15 years (1). Of these, more than $70 \%$ live at home with the majority of care provided by family and friends .

Nighttime activity is a significant problem in home-dwelling dementia individuals. A number of researchers have demonstrated profound changes in their sleep - wake cycle, including increases in time awake and number of awakenings during the night. Pollack, Perlick, Alexopoulos and Gonzalez found that disruptive nighttime behaviors, those that awoke the caregiver, occurred in $53 \%$ of elders enrolled in day care programs. The reasons for awakening a caregiver at night included complaints of pain, complaints of sleeplessness, wanting to talk, needing help, and wandering. The deleterious effects on caregivers' sleep and the ability to provide care often have the unfortunate consequence of institutional placement . Additionally, nighttime activity outside of the home in CI individuals can result in death . Thus, interventions developed to improve caregiver sleep may prevent injuries and delay institutional placement. The following case study illustrates a novel method designed to assist caregivers in managing the nighttime activity common in dementia.

\section{CLINICAL SETTING}

The initial contact with the clients occurred in a research study on nighttime activity in community-dwelling persons with dementia in May 1997. Subsequently, the couple was followed for 8 months as clients of a dementia clinic during which interventions for nighttime activity were initiated. Following is an account of a novel use of a prototype home monitoring system to manage the dementia individual's nighttime activity.

\section{HISTORY}

Mr. G., 71, was diagnosed with dementia due to probable Alzheimer's disease 1 year prior to the initial contact. His primary symptoms included loss of recent and remote memory, inability to perform instrumental activities of daily 
living, inability to drive, agitation and confusion. His disability required him to retire from his job 1 year ago. In May 1997, he was fully ambulatory, energetic, pleasant, and able to converse normally. His impression of his condition was that he had some trouble with his memory but otherwise was fine. He was unaware that he had dementia. During conversation, he was adept at covering for his memory loss. Other current medical diagnosis - atrial fibrillation treated with warfarin, digoxin, diltiazem and quinidine.

Mrs. G., 64, had retired from a nursing assistant position several years earlier due to a back injury. She provided fulltime care for her husband in their home. Mrs. G. had no significant health problems. In May 1997, she reported that the primary caregiving problems included his diminishing ability to appropriately care for himself (dressing, toileting, etc.), and being awake and out of bed during the night hours. Mrs. G. was very concerned that her husband would jeopardize his safety by leaving the home at night without her awakening. Mr. G had in fact attempted to leave the home at night on one occasion, but his stopped when his wife awoke.

\section{PHYSICAL EXAM - MR. G. (MAY 1997)}

Neurologic: Alert and oriented to place (his home). Able to freely converse although primarily used generalizations to answer questions and had details of recent events incorrect. He scored 19 on the Mini-Mental Status Exam indicating moderate dementia with the primary deficits occurring in time orientation; attention and calculation; and recall. On the Clock Drawing Test, he scored 4, indicating significant apraxia. There was good strength in all extremities and gait was normal.

Sleep: As part of their involvement in the initial research study, their sleep was evaluated using actigraphy for 7 continuous nights in May 1997. Actigraphy is a technology that allows unintrusive measurement of sleep-wake cycles. A wristwatch size device is worn on the nondominant wrist and collects and stores continuous activity data. The data are downloaded and sleep-wake cycles are analyzed using software programs developed by the manufacturer. This instrument has demonstrated reliability and validity for measuring 24-hour activity and determining sleep patterns .. Actigraphic data for 3 nights are presented in Figure 1 for Mr. G. and in Figure 2 for Mrs. G. In the figures, movement is recorded as black spikes in 30 second epochs. Sleep is indicated by a solid red line at the bottom of each day's recording. Both recordings have the caregiver's sleep interval shaded green (the time between retiring and arising). Mr. G.'s extensive activity during this green shaded period indicates the amount of nighttime activity while the caregiver was in bed, confirming the caregiver's concern about safety at night.

The data that is retrieved from the actigraphic device are presented in Table 1. Mean sleep and wake times for 7 consecutive nights detail the extensive waking of Mr. G. While it appears Mrs. G. is receiving adequate sleep, this sleep comes in shortened cycles with each cycle lasting an average of 65 minutes (range 45 - 93 minutes). Since normal restful sleep cycles average 90 minutes, Mrs. G.'s sleep is of poor quality and does not allow for feeling well rested upon waking. It is also apparent that Mrs. G. sleeps through much of her husband's night activity and validates her concern for his safety at night.

\section{CLINICAL COURSE}

In October 1997, Mrs. G. sought evaluation for her husband at our Alzheimer's Disease Assistance Center because of a rapid progression of Mr. G's symptoms over the summer. There was a significant progression in his dementia symptoms (passivity, inability to complete simple tasks) and progressive deterioration in his ability to ambulate. Clinical examination revealed evidence of a recent small stroke and Parkinson's disease. Because Mrs. G. was increasingly concerned about his nighttime activity, a prototype nighttime monitoring system was installed in their home (see description below). In January 1998, nighttime awakening suddenly increased with attempts to leave the home during the night increasing from rare to several times per night. The resulting caregiver fatigue and concern for safety precipitated nursing home placement in May 1998.

Intervention for nighttime activity: As a part of my research program, I am developing a night monitoring system to assist caregivers in managing nighttime activity. A prototype of this system was used to assist this couple from October 1997 to May 1998. The system consisted of a door opening detector on the front door (the only exit door the CI individual could independently open) and a motion detector just outside the CI individual's bedroom.

In order to ensure no unalarmed exits occurred, the front door was redundantly monitored by two alarms using different technologies typical in commercially available home alarm systems (X-10 which uses the homes electrical wiring and infrared sensors). Magnetic sensors were installed across the door opening so that opening the door 
several centimeters would cause the system to alarm. A loud, noxious alarm sounded in the caregiver's separate bedroom.

The loud alarm ensured that caregiver would be awakened to attend to this imminently dangerous situation. The system continued to sound until the caregiver arose and reset the alarm at the front door. Thus the caregiver was unable to reset the alarm without ensuring there was not an unsafe situation at the front door. There was no alarm at the front door to prevent startling the CI individual and a worsening of his confusional state. With the redundant system, there were no known false negative or false positive alarms.

Because this family lived in a small apartment, Mr. G.'s motion out of the bedroom could be monitored with a signal motion detector with the beam set across a door between the bedroom and living room. When this infrared alarm was activated, a soft, intermittent beeping alarm sounded in the caregiver's bedroom. This allowed the caregiver to be more gently alerted that Mr. G. was active in the home at night. This alarm did not require resetting but terminated after 5-7 beeps. A motion-activated light also turned on in the living room when Mr. G. left the bedroom to improve safety of the environment. While this alarm also seemed to be very accurate, it did not result in caregiver awakening with every activation. Mrs. G. recalled several occasions in which the sounding of the front door alarm due to Mr. G.'s attempt to leave the apartment awoke her from a very sound sleep.

The entire system was connected to a commercially available timer which automatically activated the system at Mrs. G.'s normal bedtime, and deactivated it at her normal rising time. The system was tested nightly by the caregiver by opening the front door before she retired. During these actuations, the redundant front door alarm performed correctly. When Mr. G. began attempting to exit the home 2-3 times per night, the system correctly alarmed with each opening of the front door.

\section{EVALUATION}

A Nighttime Activity Worry scale, a $100 \mathrm{~cm}$ visual analog scale developed by the author, was used to determine the changes in concern about nighttime activity upon installation of the prototype system. This was administered preinstallation, at week 1 and 2 postinstallation, and again at 7 months postinstallation when the nighttime activity accelerated. The results are displayed in Table 2 . Appropriate to the high level of unsafe night activity, the caregiver's worry increased on the items of leaving the home and injury. However, all items about the system being of help in relieving worry improved dramatically. The caregiver stated in interviews that the prototype-system identified attempted exits for which she would not have awoken, greatly helped her cope with the nighttime activity, and likely prevented significant injury or death of her husband. She wrote, "I never could have kept (Mr. G.) home as long as I did without your help".

The prototype device appeared to function well. There were no false positives with the device, thus Mrs. G. was not unnecessarily awakened further worsening her sleep. Without extensive home monitoring, it is difficult to determine if there were false negative alarms. Mr. G. never successfully left the home at night, nor did Mrs. G. ever identify a situation in which the door was open and the alarm not activated. The device performed correctly when it was tested nightly by Mrs. G. In further study of the monitoring device, more specific testing will need to be done to determine its reliability.

Mr. G. sustained no injuries during his nighttime activity. Additionally he never successfully left the home at night, certainly preventing significant injury as these exits would have occurred in the extreme weather of winter nights in upstate New York. He was admitted to long term care in May 1998 secondary to concerns regarding his safety and extreme caregiver fatigue from this constant nighttime activity.

\section{APPLICATION TO PRACTICE}

Nighttime activity in CI individuals is a predominant reason for long term institutional placement. It is critical for the advanced practice nurse to evaluate the presence of this symptom in each CI patient and evaluate the sleep needs of the caregiver. Since caregiver sleep disruption is characterized by fragmentation of sleep, it is important to assess the quality of sleep, as well as the duration of sleep. Appropriate symptoms to be assessed would include: difficulty falling asleep or early awakening, not feeling rested upon waking, feelings of sleepiness during the day, and changes in mood such as depression, anxiety or irritability. Caregivers identified with sleeping problems need interventions to assist in managing nighttime activity to delay nursing home placement of the dementia individual.

\section{SUMMARY}

The prototype monitoring system described here was built using off-the-shelf home security equipment. Modifications were made to ensure that the alarm sounded only at the 
caregiver's bedside, the caregiver could differentiate unsafe situations, automatic activation during night sleep period of the caregiver, and a redundant alarm was placed on the door to the outside. Work is currently underway to build and test a home monitoring system specifically for CI individuals awake at night.

\section{Figure 1}

Table 1: Actigraphic sleep data

\begin{tabular}{|l|c|c|c|}
\hline & Sleep (hrs) & Wake (min) & \% sleep during night \\
\hline Cr individual & $\begin{array}{c}5.1 \\
(3.8-6.6)\end{array}$ & $159.4(90.0-204.0)$ & $\begin{array}{c}65 \\
(52.7-79.2)\end{array}$ \\
\hline $\begin{array}{l}\text { Caregiver } \\
\text { [mean (range)] }\end{array}$ & $\begin{array}{c}7.4 \\
(6.8-8.8)\end{array}$ & $(7.5-25.5)$ & $(94.4-9.4$ \\
\hline
\end{tabular}

\section{Figure 2}

Table 2: Nighttime Activity Worry scale $-100 \mathrm{~cm}$ visual analog scale

\begin{tabular}{|l|c|c|c|}
\hline & Sleep (hrs) & Wake (min) & \% sleep during night \\
\hline CI individual & $\begin{array}{c}5.1 \\
(3.8-6.6)\end{array}$ & $159.4(90.0-204.0)$ & $\begin{array}{c}65 \\
(52.7-79.2)\end{array}$ \\
\hline $\begin{array}{l}\text { Caregiver } \\
\text { [mean (range)] }\end{array}$ & $\begin{array}{c}7.4 \\
(6.8-8.8)\end{array}$ & $\begin{array}{c}16.5 \\
(7.5-25.5)\end{array}$ & $(94.4-98.3)$ \\
\hline
\end{tabular}

\section{Figure 3}

\begin{tabular}{|c|c|c|c|c|}
\hline & $\begin{array}{l}\text { before } \\
\text { installation }\end{array}$ & \begin{tabular}{c|}
1 \\
week \\
after
\end{tabular} & \begin{tabular}{c|}
2 \\
weeks \\
after
\end{tabular} & $\begin{array}{c}7 \text { months } \\
\text { after }\end{array}$ \\
\hline $\begin{array}{l}\text { How worried are you that your spouse } \\
\text { vill leave the home ot night vithout you } \\
\text { knoving }{ }^{1}\end{array}$ & 92 & 78 & 74 & 98 \\
\hline $\begin{array}{l}\text { How concerned are you that your spouse } \\
\text { vill be injured at night }{ }^{1}\end{array}$ & 44 & 50 & 48 & 95 \\
\hline $\begin{array}{l}\text { Do you feel that the alarming of the } \\
\text { outside doors (would) relieved your } \\
\text { vorry about your spouse being up at } \\
\text { night }{ }^{2}\end{array}$ & 87 & 98 & 95 & 98 \\
\hline $\begin{array}{l}\text { Do you feal that the alarming of the } \\
\text { outside doors (would) relieved your } \\
\text { vorry about your spouse being ingured } \\
\text { at night }{ }^{2}\end{array}$ & 51 & 47 & 53 & 92 \\
\hline $\begin{array}{l}\text { Did (vould) the inside monitoring } \\
\text { system relieve your worry about your } \\
\text { spouse being up at night }{ }^{2}\end{array}$ & 45 & 78 & 69 & 96 \\
\hline $\begin{array}{l}\text { Did (would) the inside monitoring } \\
\text { system relieve your worry about your } \\
\text { spouse being injured at night }{ }^{2}\end{array}$ & 85 & 51 & 58 & 89 \\
\hline $\begin{array}{l}\text { Was (will) the monitoring system (be) } \\
\text { of help in determining where your } \\
\text { spouse was during the night }{ }^{2}\end{array}$ & 39 & 61 & 97 & 95 \\
\hline
\end{tabular}

Figure 1 - Actigraphic Sleep Recording for Mr. G

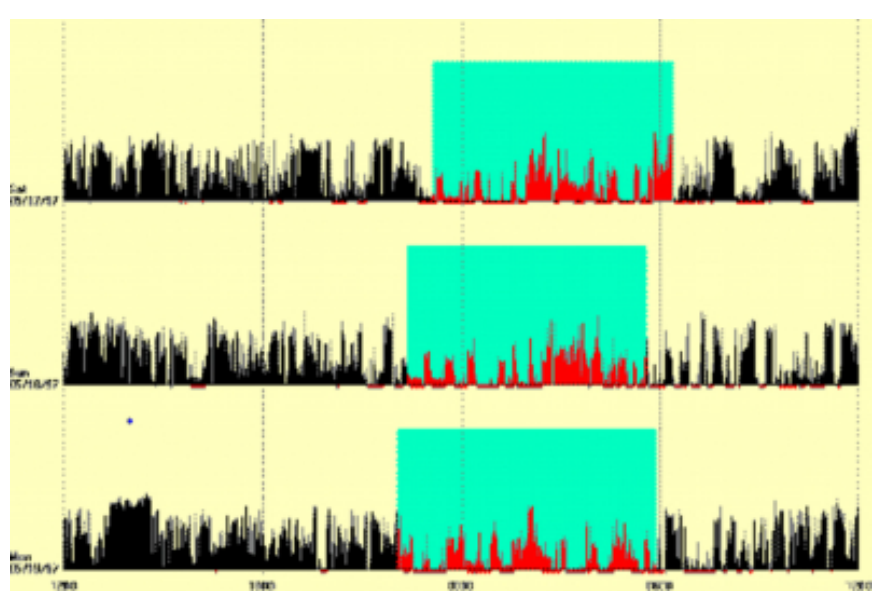

Figure 5

Figure 2 - Actigraphic Sleep Recording for Mrs. G

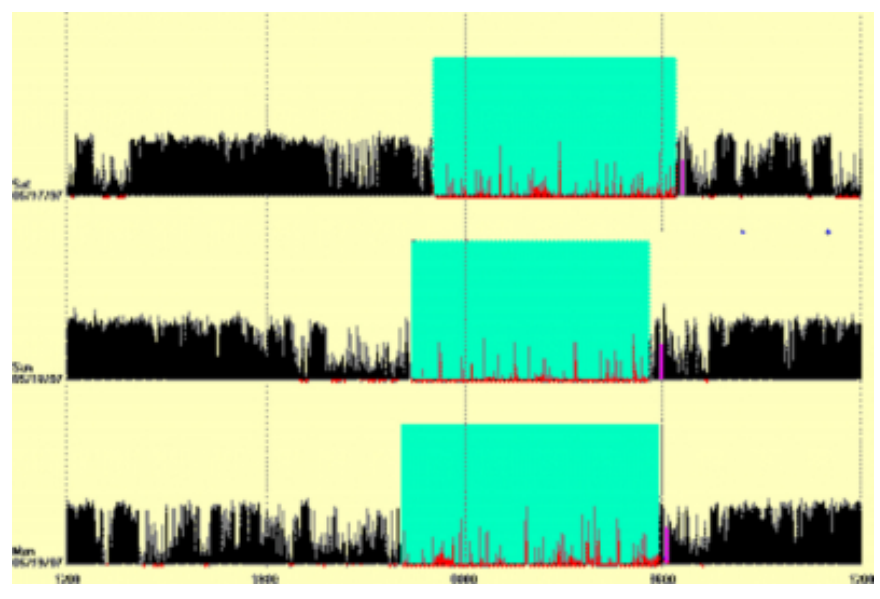

Legend for Figure 1 and 2:

Each line represents one 24-hour period of recording starting at noon. Black spikes record frequency of movement with largest spikes indicating high activity in that epoch. Sleep is indicated by a solid red line drawn at the bottom of each recording. Green shading indicates the time the caregiver retired and arose each day. Purple shading indicates the device was removed.

\section{References}




\section{Author Information}

Meredeth A Rowe, RN, PhD

Decker School of Nursing, Binghamton University 